\author{
${ }^{1}$ A.K. Shametov ${ }^{*},{ }^{2}$ R.K. Bigalieva, \\ ${ }^{3}$ E.T. Zhamburshin, ${ }^{1}$ B.E. Shymshikov, \\ ${ }^{4}$ A.C. Kulumbetov, ${ }^{1}$ Z.K. Idrisova, ${ }^{1}$ A.B. Bigaliev
}

\begin{abstract}
${ }^{1}$ School of Biology and Biotechnology, Al-Farabi Kazakh National University, Almaty, Republic of Kazakhstan
${ }^{2}$ Kazakh-American Medical University, Almaty, Republic of Kazakhstan

${ }^{3}$ Sh. Esenov Caspian technology and engineering university, Aktau, Republic of Kazakhstan

${ }^{4}$ S.D. Asfendiyarov Kazakh National Medicine University, Almaty, Republic of Kazakhstan

*E-mail: aitkhazha@gmail.com
\end{abstract}

\title{
Biological and genetical consequences of radiation effects
}

\begin{abstract}
Biologically and genetically consequences of radiation action. Consequences which emanation influence causes in a live organisms in particular could be classified by different ways depending mainly from the size of received doze. These consequences of radiation we shall enumerate in following order: changes in somatic cells leading to cancer appearance; genetic mutations rendering influence on future generations; influence on germ and fetus as a consequence of mother's radiation during period of pregnancy; death exactly at moment of radiation. Biological consequences are: changes in organism's cells leading to cancer appearance and mutations in sexual cells rendering influence on future generations. They are the most frequently connected with situation when huge number of people are influenced by small doses of radiation during expositions at medical aims or as a result of work on atomic electricity stations. Influence of radiation on developing germs or fruit presents itself special case worth of special discussion.
\end{abstract}

Key words: radiation, radiation contamination, radioactivity, ecology, mutation animals.

A quantitative characteristic of emanation is usually called a doze, which is measured in sizes of energy consumed by tissues. Number of used measurement units should be strictly determined and justified in order to make compareness possible of radioactive effects. Regretfully at present time additional misunderstanding appears conditioned by that radiation measurement units were permanently replaced in frames of International system if units. International commission for radiological units and measurements were adopted, that new units of measurement although were introduced in 1980 year but they were used simultaneously with old ones until 1984 year i.e. that time when old units were excluded from use. It should be agreed that total use in science system of International measurement units differed by their concordance and simplicity finally would bring only benefit [1].

Difference between external and internal radiation of organism. Basic understanding of radiation diseases mechanisms is clear imagination about existence of two different ways by which emanation reaches organisms tissues and influences on them. First way - external radiation from source situated outside organism. In this case X-ray emanation and $y$-rays should have relatively bigger energy on order to go through body of man and some high energy b-rays should be in position to penetrate surface layers of skin. Second way - internal radiate condition by radioactive substance come inside of organism. In this situation a-, b- and y-emanation could create serious danger. However the most threatening problem appears in case of deflection in organism of isotopes emanating a-particles with short run and high density of ionization. From all said above it follows that measures of precaution which are against external radiation totally differ from measures directed against internal radiation [2].

Norms of radiation security. From work experience with toxic substances it is known that for population more strict limits of exposition are established than for persons who are rendered for harmful influence during their working day. Justification of such position is in that it is better to go for increased risk

Printed in Kazakhstan 
in professional activity than to allow for harmful influence to spread on all population making many millions of people. These limits are known as «standards» or «norms of protection». Doctors and scientists working with X-rays in hospitals, works in Almaty occupied in many other districts of atomic industry are influenced by radiation thanks to their profession. Usually during fulfillment they are rendered to certain radioactive influence. In such situations quarter maximal affordable equivalent doze makes $30 \mathrm{mZv}$ under the condition that summarized annual doze at average should not exceed MZv for persons elder than 19 years, Maximal equivalent doze in bars shouldn't exceed size $5(\mathrm{~N}-18)$ where $\mathrm{N}$ - age of man in years. For eighteen years old doze should be limited $50 \mathrm{mZv}$ a year and for persons of elder age annual doze should not exceed $120 \mathrm{mZv}$ under the condition that in none of the year quarters they wouldn't get more than $30 \mathrm{mZv}$. If quarter limit is exceeded about this in accordance with law should be reported to Commission for control by atomic energy use or in local controlling body [3].

Consequences which emanation influence causes in alive organisms in particular could be classified by different ways depending mainly from the size of received doze. These consequences of radiation we shall enumerate in following order: changes in somatic cells leading to cancer appearance; genetic mutations rendering influence on future generations; influence on germ and fetus as a consequence of mother's radiation during period of pregnancy; death exactly at moment of radiation. Biological consequences are: changes in organism's cells leading to cancer appearance and mutations in sexual cells rendering influence on future generations. They are the most frequently connected with situation when huge number of people are influenced by small doses of radiation during expositions at medical aims or as a result of work on atomic electricity stations. Influence of radiation on developing germs or fruit presents itself special case worth of special discussion [4].

Influence of radiation on developing germ or fetus presents itself special case worth of special discussion as far as all efforts should be directed on it exclusion. Appearance of fourth effect exactly death directly during the moment of emanation is connected with receiving of huge radiation doze. Last effect appears only in catastrophic situation for example during the explosion of atomic bomb or accident on nuclear reactor.

From literature it is known that the main category of mutations are genetic changes. So, $50 \%$ in spontaneous abortion cases to emergence of domi- nant mutations. $96 \%$ of newborn cases the hereditary defects caused by gene mutations. In $4 \%$ cases are the chromosomal changes in form of number or structure of chromosomes [5].

After accident at the Chernobyl nuclear power plant a sample survey of children living in regions near the Chernobyl nuclear power plant was conducted. The results indicate a statistically significant increase in individual and group frequencies of aberrant cells and different types of aberrations in the age groups of the population living in areas with high background radiation [6].

As a result of cytogenetic survey of Ukraine's population, which is living in the radioactive fallout after the Chernobyl accident found that at the living population the incidence of aberrations of chromosome type increased, especially radiation markers (dicentrikes, doughnut and abnormal chromosomes), i.e. it is almost 8 times exceeded the reference level for these mutations, making up 0.4 and 0.44 per 100 metafazes (control of 0.05 to 100 metafazes) [7].

Among the factors leading to abnormalities of chromosomes, particular importance is attached to ionizing radiation, as all types of exposures to cause chromosomal aberrations in germ and somatic human cells.

Japanese scientists were studied chromosomes in blood leukocytes of people exposed to radiation in the atomic bombing of Hirosima and Nagasaki Awa et al., [1978], study showed that chromosomal alterations of blood leukocytes are cases to cause at the people even after three decades after the explosion were made.

Cytogenetic analysis of peoples' blood leukocytes who received irradiation was conducted by Sofuni [8]. It was showed that all irradiated persons have leukocytes, among which more than $10 \%$ had chromosome restructuring.

Results of epidemiological and experimental studies pointed out on the induction of genome instability in the offspring of parents, which were exposed to ionizing radiation. This genome instability, first of all, is happened with increase rate of mutation rate and an increased risk of .cancer and other pathologies appearance at the offspring [9].

Many scientists, research show that phenomenon of genomic instability is found in irradiated populations of distant descendants. At the same time, emergence of different types of chromosomal aberrations in cells and increase in overall level of chromosome abnormalities is appearing. Antushevich A.E. and other [10] showed on experiment that prolonged low-intensity radiation can cause a sig- 
nificant increase in the number of cells with chromosome aberrations and reciproces translocationes of chromosome not only in the exposed, but in their descendants of the first generation and especially at the second generation.

Up to date, cytogenetics have studied the patterns' activity of different genotoxic agents and has large enough factual material on the dynamics and diversity of types of chromosomal aberrations, leading to formation of difficult recovery double breaks of DNA. The study of new molecular mechanisms of cytogenetic damages education dedicated to the work of many scholars

The population living in the region of Semipalatinsk nuclear range level of diseases of blood and blood-forming organs with the dose of irradiation 90.0 Mzv in 2-2,5 times higher than level of control dose and $7.0-35.0 \mathrm{Mzv}$ in $1.3-1.5$ times correspondingly.

In the structure of blood and blood-forming organs diseases the iron-deficiency anemia is dominated, the radiation level of which at the dose of $90-$ 199,0 in 1,5-2 times higher than in the control group.

Along with extensive preventive work among population to improve feeding supply, the focus of which is to identify the light forms of anemia, it is essential to conduct screening tests, to detect abnormalities at cellular level and functional changes of the disease, namely:

- to prevent anemia among 264000 women and children up to 5 years in regions affected by nuclear testing, by improving knowledge of the pathogenesis of anemia and rationalization of nutrition.

- large-scale prevention of anemia among woman and children population, with the account of rational nutritional and ferrum-therapy.

- study of citomorfometrical indicators of peripheral blood at pregnancy anemia to develop early diagnostic and prognostic criteria of anemia and allocation of risk group.

- analysis of intracellular mechanisms development of mother and child anemia.

Environmental impact assessment of the products of nuclear explosions on the human population and development of diagnostics, adjustment and rehabilitation of population health, is the overriding priority at the present day. To do this, it is necessary to carry out:

- genetic risk assessment of many years effect of nuclear tests on gene pool of human populations,

- diagnosis of physiological state of people organism who have been influenced by many years of nuclear tests,

- diagnosis of mental condition of people who have been influenced by many years of nuclear tests,
- rehabilitation of population health by detoxification methods using antioxidants.

\section{References}

1. Dubinin N.P. et. al. The human genes found and environmental mutagens. // UdSSR Academy of Science. - 1990. - No. 1. - pp. 19-31.

2. Bigaliev A.B. et. al. Assessment of environmental pollution effects and consequences / risk on biota and public health // V-congress VS Genetics and Selection. - Moscow, 2009. - P. 372.

3. Bigaliev A.B., Bigaliev A.A. Radiation genetic and ecology problems in Kazakhstan at the environment polluted condition // Medical journal. - 2007. - No. 7. - pp. 11-16.

4. Bigaliev A.B. et. al. Mutagenic effects of radiation and prognosis of the inherited pathology of the population of the regions adjoining to the former Semipalatinsk nuclear tests site // The materials of international conference of Genetics Society of China (Synzjan University. 25-27 August). - China, 2007. - P.148.

5. Bochkov N.P., Kuleshov N.P. et al., Population cytogenetic investigation of newborns in Moscow // Humangenetik. - 1975. - No. 22 (2). - pp. 39-52.

6. Shevchenko V.A., Ramaya L.K., Pomerantseva M.D. Genetic effect of J-131 reproductive cells of male mice // Mutation Res. - 1989. - V. 226. No.1. - P. 87-91.

7. Pilinskaya M.A., Dibskiy S.S., Dibskaya E.B., Shvaiko L.I. Radiation-induced modification of human somatic cells' chromosome sensitivity to the testing mutagenic exposure of bleomycin in vitro in lung cancer patients in delayed terms following chernobyl accident // Cytol. Genet. - 2012. - No. 46 (6). - pp. 360-365.

8. Sniigiryova G.P., Lubchenko P.N. et. al. 20 years after the Chernobyl accident Present and future // Gematology and Transfuziology. - 1994. Vol. 39(3). - pp. 19-21.

9. Atsushi Sofuni The current potential of highintensity focused ultrasound for pancreatic carcinoma // Journal of Hepato-Biliary-Pancreatic Sciences. - 2014. - No. 9. - pp. 295-303.

10. Hudoley V.V. Gens and ferments for metabolic activation in chemical carcinogenesis // $\mathrm{J}$. Ecological genetics, S-kt Pitsburg. - 2003. - No. 1. - pp. 30-35.

11. Antushevich A.E. et al. Changes in the system of cyclic nucleotides in tissues of the irradiated body // Tsitologiya. - 1988. - No. 27. - pp. 233-236. 